\title{
LABORATORY INVESTIGATION OF THE FIRST SUSPECTED HUMAN CASES OF INFECTION WITH AVIAN INFLUENZA A(H5N1) VIRUS IN BULGARIA
}

T Hadzhiolova1, S Pavlova ${ }^{1}$, R Kotseva (kotseva@ncipd.org) ${ }^{1}$

1. Department of Virology, National Center of Infectious and Parasitic Diseases, Sofia, Bulgaria

Reports of human cases of infection with avian influenza $A(H 5 N 1)$ virus have received increased public attention because of the potential for the emergence of a pandemic strain. In the end of 2005 and the beginning of 2006, avian influenza A(H5N1) virus caused outbreaks among domestic poultry and was isolated from wild swans in many European countries, including Bulgaria. Between January and March 2006, samples were collected from 26 patients who had been in close contact with ill or dead birds and developed a subsequent respiratory illness. The testing took place at the National Laboratory of Influenza in Sofia. Specific A(H5N1) assays were applied for screening (Sacace RT-PCR and real-time kit). Avian flu $\mathrm{A}(\mathrm{H} 5 \mathrm{~N} 1)$ virus was not detected in any of the patients tested. In three patients, human subtype $A(\mathrm{H} 1 \mathrm{~N} 1)$ influenza virus, identifiable by RT-PCR was isolated and further characterized by hemagglutination inhibition test (HIT). The reliability of the molecular assays used in this investigation was demonstrated in an International Quality Control for Human and Avian A(H5N1) Influenza performed later in 2006 by INSTAND (Society for Promotion of Quality Assurance in the Medical Laboratories), Germany.

\section{Introduction}

Avian influenza (AI) viruses are divided into those of high and low pathogenicity (HPAI and LPAI). In domestic poultry, infection with LPAI may go undetected and usually causes only mild symptoms. However, the highly pathogenic form spreads more rapidly, and has a mortality rate that can reach $90-100 \%$ often within 48 hours. Influenza virus type $\mathrm{A}(\mathrm{H} 5 \mathrm{~N} 1)$ is highly pathogenic and very infectious for a number of bird species including most poultry species kept domestically. $A(H 5 N 1)$ virus does not usually infect people, but infections with these viruses have occurred in humans, with first cases detected in 1997, in Hong Kong. Most of the human cases have resulted from people having direct or close contact with $\mathrm{A}(\mathrm{H} 5 \mathrm{~N} 1)$-infected poultry or $\mathrm{A}(\mathrm{H} 5 \mathrm{~N} 1)$-contaminated surfaces. Although avian influenza viruses are currently poorly adapted to humans, the potential remains for the emergence of new pandemic strains either directly from avian viruses, or from their recombination with human or other animal viruses. $[1,2,3,4]$.

In the end of 2005 and the beginning of 2006, avian influenza virus $\mathrm{A}(\mathrm{H} 5 \mathrm{~N} 1)$ caused a number of outbreaks among the poultry in countries close to Bulgaria, including Turkey, Romania and Ukraine $[5,6,7]$. In addition, Turkey registered its first two human cases of $A(H 5 N 1)$ infection in January 2006. During this period the virus has also been isolated from wild swans in many European countries [6]. In Bulgaria, the National Veterinary Services detected four cases of $A(H 5 N 1)$ infection in wild swans at the Black Sea coast and along the Danube river, in January $2006[6,8]$.

In response to the increased circulation of $\mathrm{A}(\mathrm{H} 5 \mathrm{~N} 1)$ avian influenza viruses at the end of 2005 and the beginning of 2006, the Bulgarian Ministry of Health reinforced its activities related to influenza surveillance and control. The National Influenza Pandemic Preparedness Plan was approved. The National Influenza Pandemic Committee and Crisis Headquarters were established. The government provided additional financing for supplying antiviral drugs, protective equipment and diagnostic kits. Measures were also taken to inform the healthcare workers and the public about the risk of possible transmission of $\mathrm{A}(\mathrm{H} 5 \mathrm{~N} 1)$ virus among poultry and to humans.

In addition to these actions, the screening of potential human cases of infection with avian influenza virus $\mathrm{A}(\mathrm{H} 5 \mathrm{~N} 1)$ was undertaken. This required putting in place effective diagnosis not only of human influenza infections, but of avian influenza infections as well.

The laboratory identification of influenza virus infections is commonly accomplished by antigen detection, isolation in cell culture, or detection of influenza-specific RNA by highly sensitive and specific reverse transcriptase polymerase chain reaction (RT-PCR). This method, including genome detection tests, was subsequently adapted and tested during the investigation of the first suspected human cases of avian influenza $A(\mathrm{H} 5 \mathrm{~N} 1)$ virus, as described below. [9]

\section{Methods}

For the purpose of the investigation, patients who experienced influenza-like symptoms and had been in close contact with ill or dead birds or had a history of travel to countries with registered human and and/or animal avian flu cases were considered suspected cases of $A(H 5 N 1)$ infection. Samples taken from these patients were sent to the National Laboratory of Influenza for screening.

Nasopharyngeal swabs from twenty six patients and post-mortem lung and tracheal tissue and bronchoalveolar lavage specimens from two patients were available for testing. The specimens were collected in the appropriate viral transport medium (Becton \&Dickinson, USA) and were shipped immediately to the laboratory, in accordance with WHO guidelines' regulations for collection, 
storage and transport of human and animal specimens for laboratory diagnosis of suspected influenza A infection. $[10,11]$ The samples were tested immediately, or, in case it was not possible, they were frozen at $-70^{\circ} \mathrm{C}$. All the specimens were collected during the period of January to March 2006. Patients' data on sex, age and source of potential infection are shown in Table 1.

The initial specimens were screened for viral RNA by RT-PCR. RNA was extracted by using monophasic solution of phenol and guanidinium isothiocyanate-Trizol LS (Invitrogen life technologies, USA) an improvement of the single-step RNA isolation method as being developed by Chomczynski and Sacchi. [12]

For detection of avian influenza virus $\mathrm{A}(\mathrm{H} 5 \mathrm{~N} 1)$ we used the RT-PCR Avian Influenza A Virus (H5, H7) Screening and Typing kit (Sacace, Italy). For detection of human influenza viruses we applied conventional RT-PCR - One-Step Ready-to-Go RT-PCR Beads (Amersham Biosciences, U.K) kit. We used specific primer pairs for subtype $A(H 1 N 1), A(H 3 N 2)$ and for type $B(H A)$, directed against highly conserved regions of the hemagglutinin $(\mathrm{HA})$ gene segment $[13,14]$.

T A B L E 1

Suspected human cases of $\mathrm{A}(\mathrm{H} 5 \mathrm{~N} 1)$ infection investigated in the National Laboratory of Influenza in Bulgaria during the period January - March 2006

\begin{tabular}{|c|c|c|c|}
\hline Patient & Sex & Age & Potential risk factor \\
\hline 1 & $\mathrm{~F}$ & 53 & Exposure to wild bird \\
\hline 2 & $\mathrm{~F}$ & 27 & Exposure to ill bird \\
\hline 3 & M & 16 & Exposure to dead bird \\
\hline 4 & M & 21 & Chinese citizen \\
\hline 5 & M & 39 & Exposure to dead swan \\
\hline 6 & M & 45 & Exposure to dead swan \\
\hline 7 & $\mathrm{~F}$ & 11 & Exposure to dead swan \\
\hline $8^{a b}$ & $\mathrm{~F}$ & 27 & Fast food staff \\
\hline $9^{b}$ & M & 31 & Exposure to dead bird \\
\hline 10 & M & 16 & Exposure to dead swan \\
\hline 11 & M & 38 & Exposure to dead swan \\
\hline 12 & $\mathrm{~F}$ & 36 & Exposure to dead swan \\
\hline 13 & M & 48 & Turkish citizen \\
\hline 14 & $\mathrm{~F}$ & 81 & Exposure to dead swan \\
\hline 15 & M & 58 & Exposure to dead swan \\
\hline 16 & M & 54 & Exposure to dead swan \\
\hline 17 & $\mathrm{~F}$ & 54 & Exposure to dead swan \\
\hline 18 & $\mathrm{~F}$ & 38 & Veterinarian, Exposure to dead swan \\
\hline 19 & M & 60 & Exposure to dead swan \\
\hline 20 & $\mathrm{~F}$ & 22 & Exposure to dead swan \\
\hline 21 & M & 45 & Exposure to ill bird \\
\hline $22^{\mathrm{a}}$ & M & 49 & Exposure to ill bird \\
\hline $23^{\mathrm{b}}$ & M & 9 & Exposure to dead hen \\
\hline 24 & M & 36 & Exposure to ill dove \\
\hline 25 & M & 47 & Traveler to China \\
\hline 26 & M & 8 & Exposure to ill bird \\
\hline
\end{tabular}

a Deceased after severe influenza-like-illness

b Isolated human subtype A(H1N1) viruses A/New Caledonia/20/99-like. Identified by HIT
Influenza virus $\mathrm{A}(\mathrm{H} 5)$ RNA from the commercial kits or standard laboratory human influenza strains $A(H 1), A(H 3)$ and $B(H A)$ were used as positive controls; $\mathrm{ddH} 2 \mathrm{O}$ were used as negative controls. Viruses were isolated from those samples that were positive in the RT-PCR by one passage in the Madin-Darby canine kidney (MDCK) cell line and two subsequent passages in embryonated chicken eggs [13]. Viral isolation was carried out for the period of 7-10 days. The isolated strains were identified by hemagglutination inhibition test (HIT) using either WHO Influenza Reagent kit for identification of influenza isolates-2005-2006 or laboratory antisera to different human influenza $A(\mathrm{H} 1 \mathrm{~N} 1), A(\mathrm{H} 3 \mathrm{~N} 2)$ and $B$ standard strains.

In 2006, the National Laboratory of Influenza and Acute Respiratory Diseases also underwent an International Quality Control (IQC) facilitated by the Society for Promotion of Quality Assurance in the Medical Laboratories (INSTAND), Germany. We received 16 simulated samples for human and avian influenza viruses and respiratory syncytial viruses (RSV) with the aim to identify their antigenic and genomic composition. This IQC consisted of two stages: the first was performed in March while the investigation of the suspected human cases for $\mathrm{A}(\mathrm{H} 5 \mathrm{~N} 1)$ was still ongoing; and the second took place in October 2006.

The specimens sent from INSTAND were screened initially by the Directigen Flu $A+B$ (Becton \&Dickinson, USA) immunomembrane assay for detection of viral nucleoprotein (NP) and differentiation of type $A$ and $B$ influenza viruses. Specific $\mathrm{H} 5$ antigen detection kit (GeNet Bio, Korea) and RT-PCR Avian Influenza A Virus $(\mathrm{H} 5, \mathrm{H} 7)$ Screening and Typing kit (Sacace, Italy) were used for detection of $A(\mathrm{H} 5 \mathrm{~N} 1)$ avian influenza virus. For detection of human influenza viruses by RT-PCR, One-Step Ready-to-Go RT-PCR Beads (Amersham Biosciences, UK) were used as described before. The IQC specimens positive for $\mathrm{A}(\mathrm{H} 5 \mathrm{~N} 1)$ by conventional RT-PCR were confirmed once more by real-time PCR using Avian A Screening \& H5N1 Typing FRT SC (Sacace, Italy), according to the two stage standard protocol of Sacace. We used the Chromo 4 (Bio-Rad, USA) real-time PCR system. Fluorescence was observed on the FAM channel for Avian A cDNA in the first stage (Real Time Amplification Kit), and on the FAM channel for Avian A cDNA H5, and on the Cy3 channel for Avian A cDNA N1. [14]

Results

On the basis of the case definition criteria, 26 patients were considered suspected cases of avian influenza (Table 1). All these patients exhibited influenza-like symptoms and either had contact with ill or dead birds or had travelled to areas affected by avian influenza. Four patients ( $\mathrm{nr}$ 8, 9, 22, 23 in Table 1) with more severe symptoms were hospitalised and two of them subsequently died ( 8 and 22). From the investigated patients, 17 were men and 9 were women. Most of them were living in areas where $A(H 5 N 1)$ viruses were found in swans.

Clinical samples (nasopharyngeal swabs) of all 26 patients and post-mortem lung and tracheal tissue and bronchoalveolar lavage specimens from two deceased patients were collected between January and March 2006 and sent for testing at the National Laboratory of Influenza.

Avian flu $\mathrm{A}(\mathrm{H} 5 \mathrm{~N} 1)$ virus as a causative agent of respiratory disease was not detected in any one of the tested patients after the screening of the initial clinical specimens by RT-PCR. 
Simultaneously performed, RT-PCR using HA specific primer pairs found three specimens positive for $A(H 1)$ human influenza viruses.

After PCR screening, influenza strains from the same patients' specimens were isolated and identified by HIT as human $\mathrm{A} / \mathrm{New}$ Caledonia/20/99(H1N1) - like viruses. This investigation was performed because an epidemic of seasonal (human) influenza was taking place at the same time.

The accuracy of molecular testing used for the detection of suspected human cases of avian influenza $\mathrm{A}(\mathrm{H} 5 \mathrm{~N} 1)$ was

F I G U R E 1

RT-PCR for detection of $\mathrm{A}(\mathrm{H} 5 \mathrm{~N} 1)$ avian influenza virus in simulated samples sent from INSTAND (Germany) for international quality control at the National Laboratory of Influenza, Bulgaria, 2006

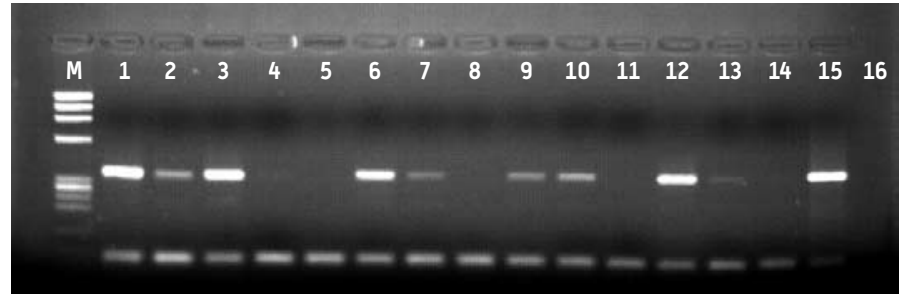

Legend: Subtyping of influenza viruses and RSV by one-step RT-PCR. Lanes 1 to 15 are simulated samples. Lanes $1,2,3,6,7,9,10,12,13$ are positive for to 15 are simulated lane 15 is $A(\mathrm{H} 5)$ positive control (Sacace kit); lanes 4, 5, 8, 11, 14, 16 are negative for $A(H 5)$; lane $M(\Phi X$ DNA) molecular size marker. Each band is $365 \mathrm{bp}$.

\section{F I G U R E 2}

Real-time PCR for detection of $\mathrm{A}(\mathrm{H} 5 \mathrm{N1})$ avian influenza virus in simulated samples sent from INSTAND (Germany) for international quality control at the National Laboratory of Influenza, Bulgaria, 2006

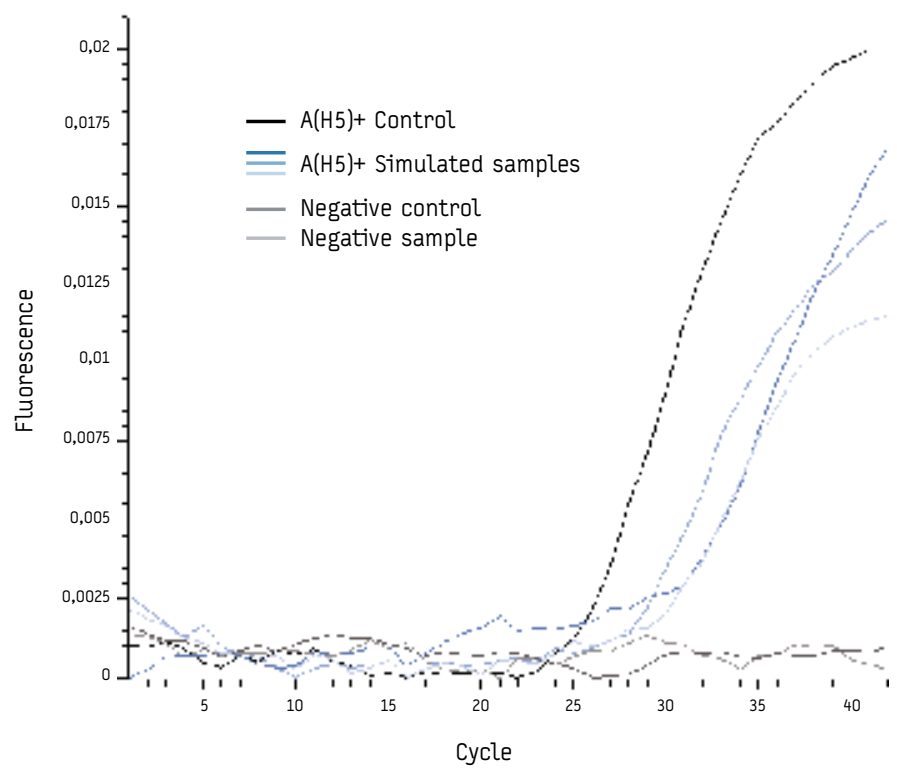

Legend: Detection of influenza A(H5) viruses by real-time PCR.

The amplification curve in black represents $A(\mathrm{H} 5)$ positive control (Sacace kit); in dark, medium and light blue - positive A(H5) samples;

in dark grey - negative control (Sacace kit), in light grey - negative $A(H 5)$ sample. demonstrated in the IQC. Nine of the 16 specimens received from INSTAND tested positive for $\mathrm{A}(\mathrm{H} 5 \mathrm{~N} 1)$ RNA by the use of conventional RT-PCR in March and October 2006 (Figure 1). The obtained sizes of the amplified products were $365 \mathrm{bp}$.

Positive results for $A(\mathrm{H} 5)$ samples from IQC were confirmed also by real-time PCR. Figure 2 shows the positive results from three simulated samples in comparison with positive and negative control from the kit.

Since 2007 the National Laboratory of Influenza and Acute Respiratory Diseases as the Bulgarian National Reference Centre has participated also in External Quality Assessment (EQA) organized by the World Health Organization (WHO), and facilitated by Virology Division of the Department of Health in Hong Kong. The results of the investigation of the simulated samples we received for testing from Panel 3 of WHO EQA in February 2008 had 100\% accuracy. [14]

\section{Discussion and conclusion}

As soon as the first cases of $\mathrm{A}(\mathrm{H} 5 \mathrm{~N} 1)$ in wild birds (swans) were detected in Bulgaria, the public health authorities considered it important to develop a more sensitive approach in defining and investigating suspected human cases of avian influenza in the National Laboratory of Influenza. In connection with the approval of the National Influenza Pandemic Preparedness Plan the National Laboratory of Influenza received the necessary equipment and tests for application of new diagnostic methods for detection of influenza viruses. The introduction of a complex of contemporary diagnostic methods was aimed to increase the preparedness of our laboratory in the conditions of a potential spread of avian influenza $\mathrm{A}(\mathrm{H} 5 \mathrm{~N} 1)$ virus.

Many countries conducted screening programmes for detection of $A(H 5 N 1)$ infection in humans. Thailand for example has large scale programme involving the testing of hundreds of people presenting with respiratory symptoms who have also had some exposure to poultry [15]. In Europe, Greece had a similar experience of examining 26 potential cases of $A(H 5 N 1)$ infection during the same period of 2006 . The tests performed with molecular methods were all negative [16].

When examining the first suspected $\mathrm{A}(\mathrm{H} 5 \mathrm{~N} 1)$ patients in Bulgaria, we followed the routine diagnostic scheme stages developed by the National Laboratory of Influenza for human influenza viruses. [13,17]

By reason of the disease severity, the necessity of rapid diagnostic response, and the lack of appropriate Biosafety level-3 (BSL-3) in our laboratory for work with highly pathogenic strains, this scheme was carried out as follows:

- Screening of the initial clinical specimens by RT-PCR for avian and human influenza viruses (BSL-2);

- Isolation of influenza viruses after obtaining negative results for A (H5N1) by RT-PCR (BSL-2);

- HIT for identification of the isolated human strains.

The investigation for $\mathrm{A}(\mathrm{H} 5 \mathrm{~N} 1)$ infection in humans described here was the first of its kind for our laboratory practice in which we had to apply the scheme in a new approach. Although none of the samples tested positive for $\mathrm{A}(\mathrm{H} 5 \mathrm{~N} 1)$ we are confident that our performance of the tests by molecular techniques (RT-PCR and Real Time PCR) was correct because as shown in the quality control testing of the simulated samples in which we obtained 
positive results for the $\mathrm{A}(\mathrm{H} 5 \mathrm{~N} 1)$ viruses. The RT-PCR and real-time PCR (Sacace, Italy) kits were adequately effective as regards the screening and genotyping of probable $\mathrm{A}(\mathrm{H} 5 \mathrm{~N} 1)$ specimens.

As described by other authors, real-time PCR finds more and more application in influenza diagnostics, due to its high sensitivity and specificity when making the diagnosis in a short period of time, and the possibility of simultaneous type and subtype differentiation of the viruses directly into the clinical specimens $[18,19]$.

In the study we performed, in the identification of the IQC specimens, real-time PCR was applied only as a quality assurance method for the confirmation of the RT-PCR result in $\mathrm{A}(\mathrm{H} 5 \mathrm{~N} 1)$ diagnostics. This was the first time this technique was applied in our laboratory practice.

The negative results obtained by $\mathrm{H} 5 \mathrm{GeNet}$ Bio when testing the IQC samples which were positive by RT-PCR make us doubt the sensitivity of this rapid test for avian influenza virus antigen detection in clinical specimens. As a matter of principle rapid antigen testing is not currently recommended for the detection of avian influenza $\mathrm{A}(\mathrm{H} 5 \mathrm{~N} 1)$ : a negative result does not exclude avian influenza, and a positive result of an antigen test (including immunofluorescence methods) does not differentiate between seasonal and avian influenza A viruses. Confirmatory testing and subtyping must be performed by molecular methods (e.g. reverse transcriptase polymerase chain reaction), virus culture or both [9].

In conclusion, the investigation of the first suspected human cases of $A(H 5 N 1)$ avian influenza virus allowed us to acquire skills needed when working with highly pathogenic infectious agents in our country and to gain the practical experience in applying the diagnostic methods necessary for the detection of influenza $\mathrm{H} 5$ antigens and genome in an extremely short period of time. The work described here has been of great importance for the public health system in Bulgaria in increasing the laboratory surveillance and preparedness. It also improved the collaboration between different institutions and persons responsible for public health in Bulgaria - epidemiologists, clinicians, human and veterinary diagnosticians working together under the direction of the Ministry of Health.
9. World Health Organization. Recommended laboratory tests to identify avian influenza A virus in specimens from humans. WHO Geneva: June 2005 Available from: http://www.who.int/csr/disease/avian influenza/guidelines/ avian_labtests2.pdf

10. World Health Organization. WHO guidelines for the storage and transport of human and animal specimens for laboratory diagnosis of suspected influenza A infection. 12 January 2005. Available from: http://www.who.int/csr/disease/ avian_influenza/guidelines/transport/en/index.html

11. World Health Organization. WHO Laboratory guidelines for collection of animal specimens for diagnosis of influenza infection. 12 January 2005 Available from: http://www.who.int/csr/disease/avian_influenza/guidelines/ animalspecimens/en/index.html

12. Chomczynski P, Sacchi N. Single-step method of RNA isolation by acid guanidinium thiocyanate-phenol-chloroform extraction. Anal Biochem. 1987;162(1):156-9.

13. Hadzhiolova T. Contemporary methods for influenza virus diagnosis and genetic characterization of influenza viruses [PhD dissertation]. Sofia: February, 2006.

14. Hadzhiolova T, Pavlova S, Kotseva R. Participation of the National Laboratory of Influenza and ARD at the External Quality Control for Antigen and Genome Detection of Influenza viruses and RSV. Infectology. 2008;1:30-33

15. Kitphati R, Apisarnthanarak A, Chittaganpitch M, Tawatsupha P, Auwanit W, Puthavathana $\mathrm{P}$, et al. A nationally coordinated laboratory system for human avian influenza A (H5N1) in Thailand: program design, analysis, and evaluation. Clin Infect Dis. 2008;46(9):1394-400.

16. Spala G, Panagiotopoulos T, Mavroidi N, Dedoukou X, Baka A, Tsonou P, Triantafyllou E, Mentis A, Kyriazopoulou V, Melidou A, Tsiodras S. A pseudooutbreak of human A/H5N1 infections in Greece and its public health implications. Euro Surveill. 2006;11(11):pii=658. Available from: http://www. eurosurveillance.org/ViewArticle.aspx?ArticleId $=658$

17. Hadzhiolova T, Pavlova S, Kotseva R. Detection and identification of human type A influenza viruses by reverse Transcriptase-Polymerase Chain reaction in Bulgaria. Lab Medicine. 2006;37:129-192.

18. Schweiger B, Zadow I, Heckler R, Timm H, Pauli G. Application of a fluorogenic $P C R$ assay for typing and subtyping influenza viruses in respiratory samples. J Clin Microbiol. 2000;38(4):1552-8.

19. van Elden LJ, Nijhuis M, Schipper P, Schuurman R, van Loon AM. Simultaneous detection of influenza viruses $A$ and $B$ using real-time quantitative PCR. J Clin Microbiol. 2001;39(1):196-200.

This article was published on 24 July 2008.

Citation style for this article: Hadzhiolova T, Pavlova S, Kotseva R. Laboratory investigation of the first suspected human cases of infection with avian influenz A(H5N1) virus in Bulgaria. Euro Surveill. 2008;13(30):pii=18938. Available online: http:// www.eurosurveillance.org/ViewArticle.aspx?ArticleId $=18938$

\section{References}

1. European Centre for Disease Prevention and Control. Influenza - avian influenza. Available from: http://ecdc.europa.eu/Health_topics/Avian Influenza/Avian_Influenza.html

2. Centers for Disease Control and Prevention. Avian influenza (Bird flu). Available from: http://www.cdc.gov/flu/avian/gen-info/facts.htm

3. World Health Organization. Avian influenza. Available from: http://www.who. int/csr/disease/avian_influenza/en/

4. Mounts AW, Kwong $\mathrm{H}$, Izurieta HS, et al. Case-control study of risk factors for avian influenza A (H5N1) disease. J Infect Dis 1999; 180: 505-508

5. Editorial team. Avian influenza H5N1 outbreaks in Romanian and Danish poultry, and large H5N1 cluster in an Indonesian family. Euro Surveill. 2006;11(21):pij=2961. Available online: http://www.eurosurveillance.org/ ViewArticle.aspx?ArticleId $=2961$

6. World Health Organization. H5N1 avian influenza: timeline of major events. Available from: http://www.who.int/csr/disease/avian_influenza/ Timeline_08\%2007\%2014\%20_2_.pdf (Accessed 20 March 2007)

7. World Health Organization. Human cases of influenza A(H5N1) infection in eastern Turkey, December 2005 - January 2006. Weekly epidemiological record. 2006;81(43):409-416. Available from: http://www.who.int/wer/2006/wer8143. pdf

8. United States Department of Agriculture. Recent Spread of Highly Pathogenic (H5N1) Avian Influenza in Birds. APHIS. May 22, 2006. Available from: http:// www.aphis.usda.gov/vs/ceah/cei/taf/emerginganimalhealthissues_files/hpai recentspread.pdf 